\title{
COESÃO SOCIAL E EFICÁCIA COLETIVA: REFLEXÕES SOBRE LOTEAMENTO FECHADO
}

\author{
COHESIÓN SOCIAL Y EFICACIA COLECTIVA: REFLEXIONES SOBRE PARCELAS CERRADAS
}

\section{SOCIAL COHESION AND COLLECTIVE EFFICACY: REFLECTIONS ABOUT CLOSED PARCELLING}

\section{BARROS, ALICE DE ALMEIDA}

Arquiteta e urbanista, Mestrado, aluna de doutorado e professora assistente da Universidade Federal de Alagoas, campus Arapiraca, alice.barros@arapiraca.ufal.br

\section{LIMA, SUZANN FLÁVIA CORDEIRO DE}

Arquiteta e urbanista, Pós-doutorado em criminologia, professora associada da Universidade Federal de Alagoas, campus Maceió, suzann@fau.ufal.br

\section{RESUMO}

O presente artigo tece algumas considerações sobre a convivência entre indivíduos moradores de loteamentos fechados que são empreendimentos residenciais horizontais delimitados por muros. Esta forma de moradia além gerar no espaço urbano diversos impactos negativos, como a fragmentação do tecido urbano e a segregação socioespacial, proporciona um convívio entre moradores, com diferentes níveis de coesão social, se materializando ou não em eficácia coletiva. O objetivo principal é realizar uma reflexão analisando os conceitos de coesão social, eficácia coletiva e o que de fato é um loteamento fechado de acordo com a legislação vigente. Para tanto, é necessário uma revisão teórica e documental, a primeira com o estudo de autores que pesquisaram e produziram conteúdo sobre o tema e a segunda se dá através da consulta a documentos e legislação sobre o tema. É possível concluir que a decisão de morar em loteamentos fechados, por parte da população, já demonstra a existência de coesão social, confiança e valores comuns levando a uma integração no convívio entre moradores, mas é preciso um análise aprofundada para ver como se materializa em eficácia coletiva, no alcance de objetivos comuns que beneficiem o coletivo.

PALAVRAS-CHAVE: loteamento fechado; coesão social; eficácia coletiva.

\section{RESUMEN}

El artículo hace algunas consideraciones sobre la convivencia entre individuos residentes de parcelas cerradas, que son emprendimientos residenciales horizontales delimitadas por paredes. Esta forma de vivienda además de generar en el espacio de la ciudad diversos impactos negativos, como la fragmentación del tejido urbano y la segregación socioespacial, proporciona una convivencia entre los residentes, con diferentes niveles de cohesión social, se materializan o no en eficacia colectiva. El principal objetivo es realizar una reflexión analizando el concepto de social cohesion, eficacia colectiva y lo que de hecho es parcelas cerradas de acuerdo con la legislación vigente. Para ello, es necesaria una revisión teórica y documental la primera con el estudio de autores que comprenden el tema y la segunda se da a través de la consulta a documentos, legislación sobre el tema. Es posible concluir que la decisión de vivir en parcelas cerradas, por parte de la población, ya demuestra la existencia de cohesión social, confianza y valores comunes, que conduce a una integración en la convivencia entre vecinos, sin embargo se necesita un análisis profundo para ver cómo se materializa en eficacia colectiva.

PALABRAS CLAVES: parcelas cerradas; cohesión social; eficacia colectiva;

\section{ABSTRACT}

This article has made some considerations about coexistence among individuals living in closed lot, horizontal residential developments delimited by walls. This way of living beyond create in the urban space various negative impacts, the fragmentation of urban mesh and the Segregation Socio-Space, provides a socializing among residentes, with different levels of social cohesion, materializing or not in collective efficacy. The main purpose is to realize a reflection analyzing the concept of social cohesion, collective efficacy and what is in fact a closed lot in accordance with the current legislation. For both, is a theoretical review and documental, the first with the study of authors who understand the theme and the second is through consulting documents and legislation about study object. Thus, concluded that a decision to live in closed parcelling, by part of the population, already demonstrates the existence of social cohesion, confidence and common values, leading a integration in socializing among residentes, but it is necessary a deep analysis to see how it materializes in collective efficacy. KEYWORDS: closed lots; social cohesion; collective efficacy. 


\section{INTRODUÇÃO}

Os loteamentos e condomínios fechados, delimitados por muros, vigiados por câmeras e seguranças, são mais visados pelos moradores que se sentem desprotegidos diante do crescimento da criminalidade nas cidades. Mas não é apenas para fugir da violência que a parcela da população procura os empreendimentos residenciais fechados, há outras questões intrínsecas no momento de escolher essa forma de morar. A vontade de viver entre pessoas com a mesma condição econômica, distanciar-se dos conflitos dos espaços públicos (barulho, trânsito, poluição, etc.), preferência por viver em um espaço homogêneo e controlado em comparação à heterogeneidade e liberdade da vida extra muros, são algumas das questões também levadas em consideração ao optar por morar em um aglomerado de casas intramuros.

O loteamento de acesso controlado (segundo a lei 13.465 de 2017), é um conjunto de casas horizontais que em muitos casos foram idealizados como parcelamento do solo para fins de loteamento (de acordo com a lei 6.766 de 1979), mas no momento da conclusão da obra ou da comercialização dos lotes foi delimitado por muros, surgindo esta forma de moradia. Os empreendimentos desse tipo possui casas com dimensões e cômodos necessários para a realização de hábitos diários para cada perfil de família, vias pavimentadas e com a devida manutenção, oferta de água, iluminação, rede de esgoto e drenagem de águas pluviais, dentre os principais aspectos. Tais espaços são dispostos nas cidades brasileiras e propostos para serem lugares ideais de segurança, lazer, tranquilidade e organização. A escolha por esse modelo específico de loteamento é por estar em crescimento na cidade de estudo Arapiraca no estado de Alagoas.

A implantação dos loteamentos no espaço urbano brasileiro expõe o fenômeno da segregação socioespacial, onde uma comunidade moradora encontra-se apartada do restante da cidade, segregada em um empreendimento delimitado por muros onde o convívio com a realidade extra muros é restrita. A segregação é social, pois o grupo morador dos empreendimentos fechados se relacionam com aqueles que possuem características culturais, econômicas e hábitos similares e a segregação é espacial, diante do fato de que a comunidade ocupa um espaço específico da cidade, limitado em dimensões territoriais, usufruindo dos benefícios dispostos dentro desses limites.

Ao mesmo tempo que os empreendimentos fechados materializam o fenômeno da segregação socioespacial em relação ao lado de fora de seus muros, expõe a existência de relações de vizinhança para dentro de seus muros. No interior desses loteamentos a convivência entre os moradores possuem diferentes níveis de integração, gerando a coesão social, baixa coesão resulta em conflitos e problemas de convivência e alta coesão intensifica relações de confiança e solidariedade. A intensa coesão social pode proporcionar que a comunidade moradora esteja organizada e mobilizada para o alcance de benefícios coletivos, gerando a eficácia coletiva, a depender do nível de coesão existente.

O tema deste artigo aborda os conceitos de coesão social e eficácia coletiva na realidade dos loteamentos residenciais de acesso controlado. Neste momento do estudo, o que importa na análise da coesão e da eficácia é o isolamento dos moradores do restante da cidade e as relações de vizinhança intramuros, a legislação aqui apresentada é importante para definir os modelos de loteamento e qual o tipo selecionado para aprofundar a pesquisa.

Dentre os procedimentos metodológicos, foram realizados dois tipos de pesquisa, a bibliográfica com o aprofundamento de estudos que tratam sobre as três palavras-chave que norteiam o trabalho, coesão social, eficácia coletiva e empreendimentos residenciais fechados, identificando pesquisas produzidas no contexto internacional e nacional, seu alcance e lacunas que podem auxiliar no desenvolvimento do trabalho. $O$ segundo tipo é a pesquisa documental com a consulta a documentos e a legislação vigente para definir os modelos de loteamentos e condomínios atualmente existentes no Brasil.

Parte da pesquisa bibliográfica buscou consultar autores que produziram estudos a partir dos conceitos, utilizados neste artigo, aplicados às diferentes realidades urbanas, são eles: Sampson, Stephen e Earls (1997), Antônio Prates (2009), Alba Zaluar e Ana Paula Ribeiro (2009), Wilson da Cruz (2010) e Robert Sampson (2011). Todos eles analisam, exceto Zaluar e Ribeiro (2009), os conceitos de coesão social e eficácia coletiva em aglomerados urbanos habitados pela população pobre. As autoras que são exceção pesquisaram a coesão e eficácia também em condomínio fechado no bairro Barra da Tijuca no Rio de Janeiro, deixando claro que há possibilidades de explorar os conceitos e buscar resultados em outras realidades.

A lacuna encontrada nas pesquisas é que a maior parte dos autores não investigou de que forma os conceitos são observados na realidade vivida pela parcela da população que habita empreendimentos fechados. Esta população ao longo dos anos tem se isolado cada vez mais em espaços delimitados para pessoas de mesma condição social, mas não se sabe ao certo se nestes lugares existe convivência que gera confiança com alcance de benefícios coletivos. Os aglomerados habitacionais, como os loteamentos e condomínios fechados, possuem potencial para que neles sejam realizadas pesquisas à luz de tais conceitos. 
As demais referências aqui utilizadas apresentam estudos de loteamentos e condomínios fechados (CALDEIRA, 2000; FREITAS, 2008; SCIOTA, 2016), segregação socioespacial (RIBEIRO, 2004; SOUZA, 2005; MOTTA, 2017). Também foi essencial consultar legislações urbanísticas a nível federal para compreender melhor quais diretrizes estão em vigência permitindo e impedindo o uso e ocupação do solo e como definem os condomínios e loteamentos para esclarecer tais nomenclaturas.

Acredita-se que a relevância da pesquisa é agregar aos estudos de coesão social e eficácia coletiva informações vindas de outros espaços urbanos, não apenas os habitados pela população mais pobre, mas analisar outras formas de habitação, como, por exemplo, moradias inseridas nos loteamentos de acesso controlado. Esta nova forma de morar nas cidades tem causado impacto negativo na produção do espaço, ocupação, gestão e cidadania, necessitando um aprofundamento na investigação dos conflitos que o morar em loteamentos pode provocar na convivência entre indivíduos.

No que se refere à estrutura do texto, para a compreensão do conteúdo, foi necessário seguir uma sequência, iniciando pela definição dos conceitos de coesão social e eficácia coletiva, com base na literatura produzida sobre $o$ assunto, expondo a materialização no espaço urbano. Em seguida, foram analisadas as mudanças que ocorrem na cidade contemporânea, destacando a implantação de loteamentos e condomínios como uma presença marcante nas cidades da atualidade, causando impactos na convivência entre indivíduos, o que justifica a aplicação dos conceitos inicialmente abordados. Finalmente, apresentam-se as leis vigentes que definem estes empreendimentos, explicitando as principais características, e a relação entre segregação e coesão nas relações com o exterior e no interior dos loteamentos de acesso controlado.

\section{A COESÃO SOCIAL E A EFICÁCIA COLETIVA}

Quando indivíduos decidem o lugar de morar, dentre os principais fatores que influenciam a escolha, está a possibilidade de estar entre pessoas que despertam a sensação de confiança e acolhimento para que haja uma convivência segura e saudável. Esta convivência acontece graças à sociabilidade que acontece entre indivíduos e os laços sociais formados durante a realização de atividades e ações no espaço e no tempo. No momento que um grupo de moradores se muda para um loteamento fechado, eles possuem objetivos comuns que os unem dentro desse mesmo espaço, por exemplo, morar em um local protegido, onde acreditam poder criar os filhos em um ambiente seguro e tranquilo.

Segundo Zaluar e Ribeiro (2009, p.178), "quando os objetivos são coletivos, a confiança adquirida na sociabilidade precisa da capacidade de mobilização e organização dentro da rede, o que integra ainda mais o cálculo à reciprocidade". Indivíduos com objetivos, valores, crenças e interesses em comuns, que passam a confiar uns nos outros, adquirem capital social, eles iniciam ao longo desse processo de descoberta de afinidades, uma intensa integração que promove a coesão social.

A palavra coesão se refere à aderência, união, ligação, associação íntima e quando se conecta ao termo social se traduz em uma forte relação que se estabelece entre as pessoas. Segundo Cruz (2010, p.43), coesão social é entendida como confiança mútua e estabelecimento de valores comuns. O mesmo autor acrescenta: "é a 'extensão da confiança local' que vai 'operacionalizar' a coesão e o funcionamento da confiança, a boa vontade em ajudar os vizinhos, a ausência de conflitos e compartilhamento de valores" (CRUZ, 2010, p.41).

Os principais aspectos que fortalecem a coesão social dentro dos loteamentos de acesso controlado são: a ausência de conflitos, pois os moradores estabelecem regras a serem seguidas em prol da ordem interna, e o compartilhamento de valores sociais, aquilo em que os indivíduos acreditam e defendem na sociedade. Outro aspecto é o entrosamento entre indivíduos através das conversas, encontros e identificação de afinidades; o controle informal em que os próprios moradores controlam atitudes desviantes sem a necessidade de intervenção externa e formal; redes de interação com a criação de eventos para possibilitar o contato entre os grupos. A estabilidade residencial e a propriedade da residência, evitando mudanças constantes de moradias, favorecem uma relação de vizinhança duradoura e confiável.

A coesão social é um dos efeitos da vizinhança e, dependendo de sua intensidade, pode gerar a eficácia coletiva. Quando um determinado grupo se une em busca de benefícios coletivos surge a eficácia; nos loteamentos de acesso controlado, os moradores impõem suas demandas para o lugar onde moram e, para isso, há uma mobilização para alcançar aquilo que desejam para o coletivo. Ao reunir disposição, habilidade e competência, o grupo estabelece os bens que se pretende conseguir e assim a eficácia coletiva acontece. Os benefícios a serem alcançados podem incluir conserto de um equipamento da área de lazer, definição de horários para a realização de eventos no salão de festas, regras de uso da quadra de esportes, definição de punição para mal comportamento de moradores, elaboração do regimento interno, dentre outros exemplos. 
No processo de coesão social, as pessoas estão tão integradas em uma rede de relações que são capazes de controlar ações desviantes e conseguir benefícios para o grupo, gerando a eficácia coletiva, em diferentes níveis. O termo eficácia coletiva foi elaborado pelos autores Sampson, Raudenbush e Earls (1997), em estudo na cidade de Chicago, na tentativa de explicar que a criminalidade não é resultado apenas da concentração de desvantagens socioeconômicas, mas possui relação com outras características sociais. Seria esta eficácia, ou seja, a capacidade diferencial que as vizinhanças demonstram em realizar os valores comuns dos moradores e em manter controles sociais efetivos sobre as pessoas em socialização, a maior fonte de variação vicinal em violência.

A eficácia coletiva é uma variável que estabelece os níveis de mobilização que uma comunidade possui para alcançar seus objetivos, necessário que o grupo social se organize para conseguir benefícios comuns, "disposição, habilidade e competência, três aspectos da eficácia coletiva de cada comunidade em se organizar para impor suas demandas à área em que moram" (ZALUAR; RIBEIRO, 2009, p.181). A organização se estabelece se existir condições de confiança e solidariedade entre os indivíduos, além da homogeneidade de padrões morais e culturais (ZALUAR; RIBEIRO, 2009, p 182). Assim poderão controlar o comportamento daqueles que fazem parte da comunidade para conseguir o bem comum. A eficácia coletiva pode existir ou não em um determinado recorte espacial onde habita um grupo de indivíduos e existem os níveis de eficácia, ou seja, se há uma alta ou baixa mobilização entre os moradores para conseguir determinado benefício para a comunidade. Tal benefício pode ser "qualquer produção de bens de natureza coletiva seja pela prefeitura seja pela ação coletiva interna, como por exemplo a mobilização interna para consertar uma calçada, ou uma praça, ou uma creche." (PRATES, 2009, p.1128).

O importante para a eficácia coletiva é a predisposição dos indivíduos em prol do bem comum e, assim, será possível manter o controle social interno através de normas, regras que facilitem o convívio e evitem conflitos. Os moradores podem ter lugares específicos dentro do loteamento onde podem sentir-se mais coesos e onde poderão definir os bens a serem buscados para a melhoria do lugar, sendo a reunião de condomínio um momento de estímulo à coesão e à eficácia ou conflitos. Da mesma forma que acontece com a coesão social, a eficácia coletiva pode ser mensurada através da maneira como a mobilização para alcançar determinado benefício acontece, a intensidade da rede de cooperação e se o benefício foi parcialmente ou plenamente alcançado.

A maior parte da literatura encontrada possui em comum o interesse em desvendar como surge a relação de convivência nas cidades, de que maneira se fortalecem e enfraquecem e quais os resultados disso para a sociedade e para o lugar de moradia. O foco principal dos estudos são as comunidades de baixa renda com restrições econômicas e baixa escolaridade, dentre os principais aspectos. A proposta é que novas pesquisas sejam produzidas aplicando os conceitos como coesão social e eficácia coletiva em diversos espaços urbanos produzidos na contemporaneidade diante das mudanças de uso e ocupação do solo, estilos de vida e modos de morar.

\section{MUDANÇAS CONTEMPORÂNEAS NO ESPAÇO URBANO}

No ritmo acelerado da vida contemporânea, os indivíduos estão em busca de suprir suas necessidades e alcançar seus objetivos e projetos de vida. Isto acontece de maneira desigual diante da distribuição de renda e benefícios no espaço da cidade e assim surgem segmentos de população: os privilegiados, os excluídos e os grupos que permeiam esses dois extremos. A interação entre as parcelas diferentes da população se torna cada vez mais difícil, à medida em que se ampliam as desigualdades sociais e econômicas e alguns grupos buscam um isolamento. A interação é muitas vezes dificultada, pois as diferenças entre grupos de indivíduos passam a se materializar fisicamente num processo de diferenciação social e espacial, onde surge 0 fenômeno da segregação socioespacial, fato que diminui as oportunidades de contato entre os diferentes e os desiguais, principalmente no que se refere ao aspecto econômico.

A elite da sociedade capitalista possui o potencial de atrair investimentos, para a área onde estabeleceu moradia, por parte de grandes empresários e do poder público, que em muitos casos necessita deste grupo social para financiar campanhas eleitorais. A elite e os demais segmentos da população, diferenciados pelos seus costumes e rendas, ocupam as partes da cidade, não de maneira que elas dialoguem, mas tais partes encontram-se segregadas, isoladas umas das outras espacialmente e com interações sociais distanciadas. "A segregação socioespacial é característica inerente ao meio urbano em economias capitalistas. Assim, "a cidade, sob a égide capitalista, é desigual, e o processo de urbanização tem produzido e reafirmado muitas das existentes injustiças e desigualdades" (MOTTA, 2017, p.3). É através do espaço urbano segregado que as desigualdades sociais se materializam com mais intensidade. Ainda sobre o tema da segregação socioespacial, o autor afirma: 
A segregação é um fenômeno que, de modo geral, materializa espacialmente a divisão social em classes e que também requer uma análise criteriosa e complexa para o enfrentamento dessa questão. No entanto, podem existir situações em que ocorre proximidade física entre grupos sociais heterogêneos com forte estigmatização e separação simbólica entre ambas as partes ou distanciamento físico entre grupos homogêneos, o que complexifica o debate do tema (MOTTA, 2017, p.3).

Aqueles indivíduos que possuem o poder de decidir o lugar de morar fazem parte de um processo chamado de autossegregação; há uma escolha, uma decisão por esse perfil de moradia. Souza (2005) aborda o fenômeno da autossegregação protagonizado pelas elites urbanas e o atribui a diversos fatores: uma paisagem urbana crescentemente marcada pela pobreza e pela informalidade; a deterioração das condições gerais de habitabilidade e qualidade ambiental nos bairros residenciais privilegiados tradicionais devido a congestionamentos, poluição do ar e etc.; a busca de uma maior exclusividade social; eventualmente, a busca de novos espaços residenciais que apresentem amenidades naturais, dentre outros.

A autossegregação ou segregação voluntária se materializa, em muitos casos, na escolha por moradias inseridas em espaços controlados. Estes espaços podem ser chamados de núcleos urbanos fechados (SCIOTA, 2016), possibilitam ao habitante ter a sensação de segurança ainda que esteja em uma área da cidade isolada e distante do centro e de bairros consolidados, escolher pelos empreendimentos fechados, é uma maneira de ficar longe de estranhos, pessoas de estilos de vida diferentes do seu, pois o controle e a autorização define aqueles que podem compartilhar daquele espaço. O sentimento de incerteza, de temor e de insegurança despertam "uma atitude constante de vigília e de alerta, na verdade, uma ampla família de atitudes de reticência permanente e um conjunto de estratégias de refúgio e privatização" (SORJ; MARTUCCELLI, 2008, p.72).

Não apenas moradores com condições econômicas satisfatórias desejam habitar nos enclaves fortificados (CALDEIRA, 2000), as classes média e baixa também se tornam moradoras destes espaços ao longo dos anos. Este estilo de morar se torna comum nas diferentes faixas de renda da população que desejam habitar espaços que consideram seguros e que possuam à disposição diversos equipamentos de lazer e possam conviver com pessoas selecionadas e longe de interações indesejadas. Este tipo de empreendimento, espaço privado e exclusivo, é considerado privilegiado enquanto os públicos, onde "há confusão e mistura, isto é, heterogeneidade social” (CALDEIRA, 2000, p.265), passam por um processo de esvaziamento.

As principais consequências de empreendimentos fechados, de acordo com Freitas (2008), são: mudança na escala da segregação e aumento dos custos sociais, degradação do meio ambiente, morte da rua e da cidade, diminuição do contato social, dentre outros. Ainda assim, esses modelos de habitação são cada vez mais comuns nos dias atuais em diferentes perfis de cidades e refletem as mudanças pelas quais o espaço urbano tem passado, podem ser os condomínios de casas ou loteamentos delimitados por muro.

Até os anos 2000, existiam muitas dúvidas sobre a definição e características de cada modelo de aglomerado residencial. A legislação urbanística aprovada ao longo dos anos possibilita uma melhor compreensão sobre essa realidade, esclarecendo questões sobre a legalidade deste tipo de empreendimento. Assim sendo, percebe-se a importância de realizar um breve levantamento das leis no âmbito nacional para esclarecer as nomenclaturas. Serão apresentadas leis vigentes de 1964 até 2017; algumas delas sofreram alterações para auxiliar na compreensão dos tipos de empreendimento.

\section{Breve análise da legislação urbanística}

A discussão jurídica aqui apresentada tem o objetivo de auxiliar na definição dos modelos de empreendimentos residenciais fechados e apresentar questões de legalidade e ilegalidade de tais modelos. Após a definição dos modelos de empreendimentos residenciais fechados, será esclarecido qual tipo foi escolhido para o estudo e por qual motivo.

O projeto de conjunto de edificações de uso residencial surge ao longo dos anos em duas principais modalidades: condomínio e loteamento. O primeiro modelo é o estabelecido inicialmente pela lei 4.591 de 1964 que dispõe sobre o condomínio em edificações e as incorporações imobiliárias. Quando o proprietário de um terreno decide construir um condomínio de edificações para uso residencial ou comercial, serão edificadas unidades autônomas, o proprietário de cada unidade autônoma (casa, apartamento, sala comercial) é coproprietário das áreas comuns (vias, áreas verdes, equipamentos). A lei 4.591 de 1964 indica que "a cada unidade caberá, como parte inseparável, uma fração ideal do terreno e coisas comuns, expressa sob forma decimal ou ordinária" (BRASIL, 1964). 
O projeto urbano de loteamento, segundo a lei no 6.766 de 1979, exige a divisão de uma gleba em parcelas e a apresentação da implantação de vias, drenagem de águas pluviais, iluminação urbana, abastecimento de água, esgotamento sanitário, locais para a construção de equipamento comunitário (voltado para educação, saúde, cultura) e espaços livres (praça, parque). As vias, equipamentos comunitários e áreas de lazer são de uso público, qualquer indivíduo pode usufruir, informação que já constava na lei 271 de 1967: "desde a data da inscrição do loteamento passam a integrar o domínio público de Município as vias e praças e as áreas destinadas a edifícios públicos e outros equipamentos urbanos, constantes do projeto e do memorial descritivo" (BRASIL, 1967).

Os questionamentos surgidos sobre como caracterizar os loteamentos e condomínios murados, a insegurança vivida pelos empreendedores no momento de propor este tipo de empreendimento e da administração municipal no ato de aprovação, pois existiam questões que geravam condições de ilegalidade, evidenciaram lacunas nas legislações. Os empreendimentos não seguiam em total conformidade a lei 4.591 de 1964 e também não obedeciam todas as exigências da lei 6.766 de 1979. Visando suprir essas lacunas, foi aprovada a lei 13.465 de 2017.

Esta lei constitui o loteamento de acesso controlado (LAC), fruto de parcelamento do solo e com delimitação física (muros, cercas) de seu entorno para que seja possível controlar a entrada e saída de pessoas, veículos e mercadorias. A compreensão do parágrafo 8o do artigo 2 é que o loteamento delimitado por muros poder ter seu acesso controlado, desde que este controle seja regulamentado por decreto ou lei aprovado pelo poder público municipal. Ainda consta no mesmo parágrafo que os responsáveis por controlar o acesso não podem impedir a entrada de pedestres e condutores de veículos, que não moram no loteamento, caso estes indivíduos possuam identificação ou estejam cadastrados.

Através da lei 13.465 de 2017, a Lei no 10.406, de 10 de janeiro de 2002 (Código Civil), passa a vigorar acrescida da Seção IV: "Do Condomínio de Lotes". Na lei 4.591/64, já citada anteriormente, o condomínio em edificações ou edilício (o de casas) não cria lotes, e sim unidades autônomas, vinculadas a uma fração ideal do solo e das áreas comuns. O artigo 1.358-A que consta na lei 13.465 de 2017 permite a criação de um condomínio de lotes, estes estarão vinculados a uma fração ideal das áreas comuns. As áreas comuns, todos os espaços de uso de todos os moradores: ruas, praças, equipamentos de lazer, não são transferidas para o município, são propriedade privada pertencentes aos proprietários dos lotes.

Em resumo, tem-se em Condomínio em edificações, da lei 4.591 de 1964: Serão edificadas unidades autônomas, o proprietário de cada unidade autônoma (casa, apartamento, sala comercial) é coproprietário das áreas comuns (vias, áreas verdes, equipamentos). Essas unidades autônomas consistem necessariamente em construções existentes, e não em lotes avulsos.

O Loteamento (lei 6.766 de 1979) é a subdivisão de gleba em lotes destinados a edificação, com abertura de novas vias, prolongamento, modificação ou ampliação das vias existentes. Desde a data de registro do loteamento, passam a integrar o domínio do Município as vias e praças, os espaços livres e as áreas destinadas a edifícios públicos e outros equipamentos urbanos.

Sobre condomínio de lotes, de acordo com a lei 13.465 de 2017, pode haver, em terrenos, partes designadas de lotes que são propriedade exclusiva e partes que são propriedade comum dos condôminos. Criação de um condomínio composto por lotes, que estarão necessariamente vinculados a uma fração ideal das áreas comuns na proporção a ser definida no ato da instituição. Na prática, as vias e áreas comuns não serão de propriedade do município, e sim de propriedade privada, pertencendo aos titulares do lote na proporção de sua respectiva fração ideal.

Loteamento de acesso controlado (13.465 de 2017) é modalidade de loteamento cujo controle de acesso será regulamentado por ato do poder público Municipal, sendo vedado o impedimento de acesso a pedestres ou a condutores de veículos, não residentes, devidamente identificados ou cadastrados. O Município concede o uso exclusivo das áreas públicas, é de propriedade pública, mas com uso cedido ao particular. A lei possibilita a instalação de portarias nas ruas com o controle da entrada de pessoas e veículos, a depender de ato administrativo do município.

Após definir o loteamento de acesso controlado para que não haja dúvidas em comparação com o loteamento de fato e o condomínio de lotes, é importante aplicar os conceitos vistos ao longo do texto (coesão social e eficácia coletiva), no objeto de estudo definido e relacioná-los com o fenômeno da segregação socioespacial para compreender as relações existentes para fora e dentro do empreendimento residencial fechado.

A aplicação dos conceitos de coesão social e eficácia coletiva pode ser realizada em qualquer um dos modelos de empreendimentos delimitados por muros. A decisão pelo loteamento de acesso controlado (LAC) é devido ao crescimento deste modelo de empreendimento na cidade de Arapiraca, Alagoas, município escolhido para ser palco das pesquisas realizadas. Após definir o loteamento de acesso controlado para que 
não haja dúvidas em comparação aos demais tipos, é importante compreender a realidade da cidade que inspira o estudo aqui apresentado.

\section{A CIDADE DE ARAPIRACA}

A cidade de Arapiraca (figura 1) encontra-se localizada no centro do Estado de Alagoas, sua população no último censo do Instituto Brasileiro de Geografia e Estatística (IBGE) em 2010 consta 214.006 habitantes, a população de 234.185 pessoas foi estimada para 2017. A localização privilegiada dentro do estado, a presença de estabelecimentos comerciais, de serviços (hospitais e bancos, por exemplo), educacionais (escolas e universidades) e lazer (parques e cinemas) atraem moradores das cidades vizinhas que não possuem este tipo de oferta em seus limites. Uma parcela dos indivíduos, nascidos em municípios menores, procura Arapiraca para estudar e trabalhar e não apenas realizam o movimento pendular, mas muitos passam a morar na cidade.

Figura 1: Mapa do estado de Alagoas com destaque para a o município de Arapiraca.

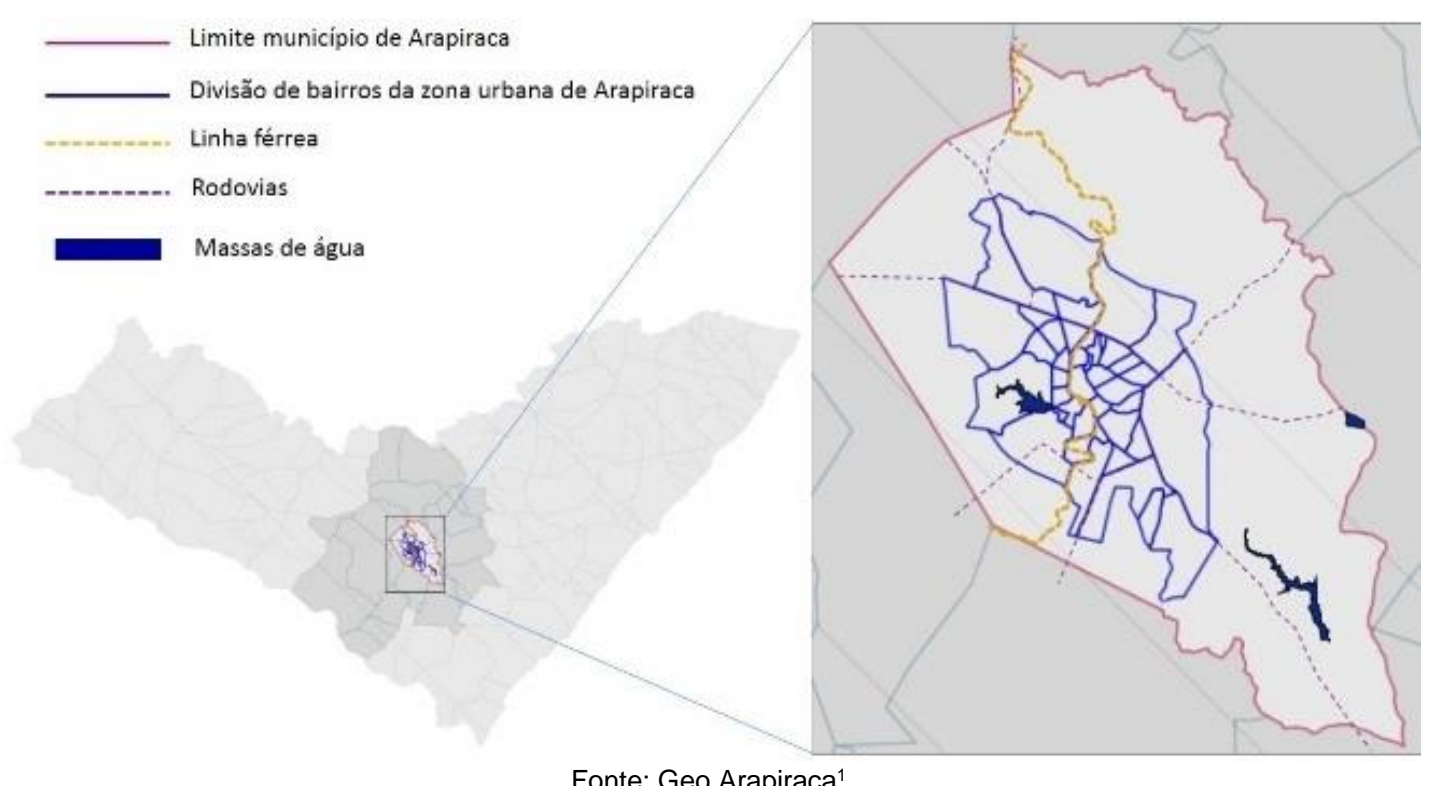

As melhorias na cidade aconteceram mais intensamente a partir de 2000 e seguem até 2004. Dentre as principais obras estão o Parque Urbano Ceci Cunha I, no bairro Centro, espaço de lazer para realização de atividades físicas e passeios com a presença de área verde e equipamentos como: quadras, pista de skate, ginásio de esportes. Outras obras, como a reforma do calçadão do comércio, mudança da feira livre das principais ruas do centro para suas extremidades, implantação do mercado público e pavimentação de grande parte dos bairros trouxeram benefícios para a população e atraíram investimentos de empresário e mais visitantes e consumidores para a cidade.

De 2005 até 2012, mais obras foram realizadas com investimento em infraestrutura urbana e na construção de equipamentos públicos. Houve a implantação do sistema de esgotamento sanitário, reforma das principais praças do centro com ampliação do Parque Ceci Cunha - Parque Urbano Ceci Cunha II, e construção do Mercado do Artesanato (2007), implantação do parque às margens do lago da Perucaba (2009), Bosque das Arapiracas (2011), inauguração (2012) do planetário Casa da Ciência com oferta de atividades educativas, bibliotecas públicas nos bairros, escolas de tempo integral, chegada da terceira adutora e subestação de energia e o primeiro shopping center da cidade.

Ao observar o mapa de Arapiraca (figura 2) percebe-se que os loteamentos residenciais horizontais, incluindo os fechados, encontram-se situados na periferia da cidade, distante do centro, pois é onde localizam-se terrenos maiores e mais baratos, alguns deles com infraestrutura deficiente. A implantação difusa no território gera o processo de dispersão urbana, expansão do tecido urbano ocasionando, como no caso de Arapiraca, o aumento do perímetro urbano. Enquanto isso, terrenos mais próximos do centro encontram-se vazios, obrigando parte da população a morar longe do local de trabalho, estudo e lazer. 
Figura 2: Posicionamento Base geral de ocupação de loteamentos por década.

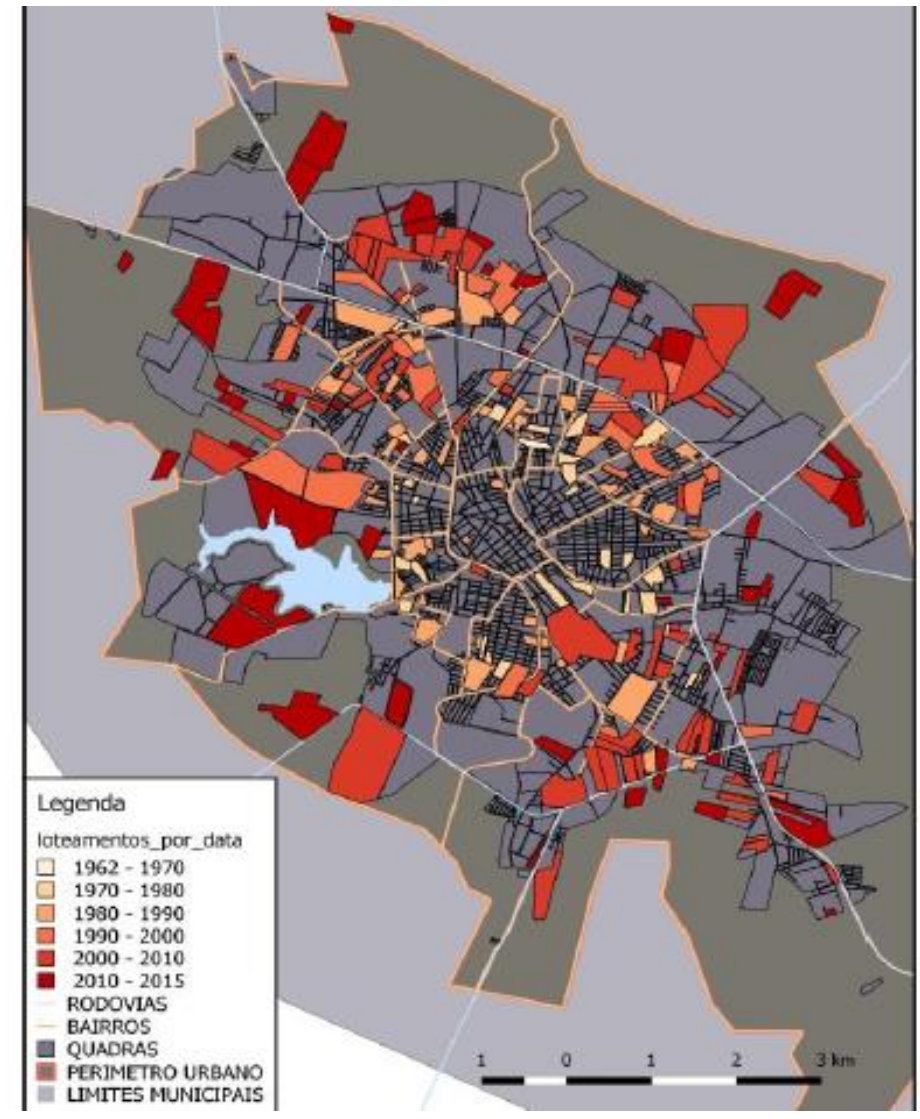

Fonte: DAMASCENO et al, 2016, p.7.

Nos primeiros anos expostos no mapa, décadas de 1960 e 1970, os loteamentos estão localizados mais próximos do Centro, alguns nos bairros imediatamente vizinhos com fácil acesso aos estabelecimentos centrais e com oferta de infraestrutura. Nas décadas de 1980 e 1990, este tipo de empreendimento passa a ocupar grandes áreas nos bairros mais periféricos da cidade, exigindo a expansão de rede de abastecimento de água, iluminação pública e rede de transporte público. Os loteamentos implantados de 2000 até 2015 estão ainda mais distantes do centro da cidade em áreas com infraestrutura insuficiente e precária, em muitos casos, apenas dentro dos limites do loteamento há condições de habitabilidade e o entorno está vazio ou habitado por famílias mais pobres.

Os loteamentos residenciais horizontais delimitados por muros foram construídos a partir de 2007, são os intitulados loteamentos de acesso controlado após 2017. Estes foram implantados de acordo com a lei federal 6.766/1979 e lei municipal 2.770/2011, onde exigem que vias de circulação, áreas verdes e equipamentos comunitários sejam de uso de público, mas os proprietários dos loteamentos passaram a privatizar tais áreas, delimitando o entorno do empreendimento com muros, cercas e equipamentos de vigilância. Nesses empreendimentos, há um controle de acesso autorizado pelo poder público Municipal que permite a instalação de portarias nas ruas com o controle da entrada.

De 2007 até 2016, foram construídos 31 loteamentos de acesso controlado (PREFEITURA DE ARAPIRACA, 2017). O surgimento de empreendimento residenciais fechados em Arapiraca, segundo Damasceno et al (2016, p.9), "está associado a uma nova tendência de ambientes privativos que estão obtendo interesse dos moradores, atraídos, sobretudo, pela infraestrutura no geral que eles oferecem, dando destaque à segurança e lazer, uma vez que no restante da cidade esses itens se apresentam de maneira escassa ou deficiente".

A ideia de delimitar os loteamentos com muros e equipamentos de segurança vem junto com o discurso do aumento da criminalidade na cidade, e que é necessário se proteger por trás de grades e câmeras de vigilância 24 horas. Mas acredita-se que este é apenas um dos motivos que levaram os indivíduos a procurar este modo de morar; é possível que fugir dos problemas dos espaços públicos (trânsito, barulho) e compartilhar o loteamento com pessoas que possuem condição econômica, valores culturais e hábitos bem 
similares podem ser outros motivos. Essa mudança na maneira de morar, que antes de 2007 era em loteamentos abertos que permitiam a livre circulação dos moradores e visitantes, passou de uma cidade com intensa relação de vizinhança com conversas na calçada das casas, passeios nas praças em diferentes horários do dia, para se transformar em um espaço urbano fragmentado com áreas isoladas onde os LAC's ocupam e segregam moradores e os distanciam do convívio com o espaço público e a diversidade da cidade.

Diante da realidade observada na cidade de Arapiraca surge o interesse em desvendar de que maneira a presença dos LAC's prejudica a eficácia e a coesão entre os moradores, pois estes saíram de loteamentos abertos, acostumados com outras formas de convivência e de experiência da cidade em direção ao modelo fechado. Existem aspectos positivos e conflitos que acontecem intramuros indicando que o fenômeno da segregação socioespacial impacta a convivência entre indivíduos dentro dos LAC's.

\section{SEGREGAÇÃO X COESÃO: RELAÇÕES COM O EXTERIOR E NO INTERIOR DO LAC}

Neste momento, apresentam-se duas formas de observar o loteamento de acesso controlado (LAC) de uso residencial e horizontal: sua relação com o exterior, com o entorno e a relação no seu interior, os efeitos de vizinhança.

Ao relacionar o espaço do LAC e o seu entorno, as construções e indivíduos que percorrem os espaços, percebe-se que há uma diferenciação do espaço, o primeiro é privado e homogêneo e o segundo é público e heterogêneo. A heterogeneidade do seu entorno se deve à diversidade de grupos sociais e seus potenciais econômicos, os diferentes espaços de moradia, liberdade de circulação de pessoas, veículos e moradias. Por sua vez, a definição de espaço homogêneo pelo fato de que as moradias do LAC são vendidas para um determinado grupo incluído em uma faixa de renda estabelecida, há um compromisso desse grupo em seguir normas e regras acordadas pelos moradores, e estes possuem nível de escolaridade, hábitos e características culturais similares.

Morar em um loteamento de acesso controlado, considerado lugar de qualidade, é ocupar uma posição importante na sociedade e estabelecer um poder econômico e social superior aos outros grupos de indivíduos que não habitam no mesmo espaço. Aqueles que detêm o poder, na sociedade capitalista, acumulam capital econômico, consomem o espaço e neles inserem as melhores condições de moradia e infraestrutura e ainda atrai investimentos por parte do poder público diante de sua importância no apoio político e investimento econômico no comércio, serviços e indústria. Habitar nesse tipo de empreendimento é escolher distanciar-se daqueles que não possuem as mesmas condições de vida e só se aproximam conforme necessidade específica e autorização.

Os efeitos da segregação socioespacial na cidade é a criação de ilhas isoladas onde os moradores estão preocupados com os benefícios ali situados e pouco se importando com os problemas encontrados para fora dos muros, desde que não atinjam diretamente sua vida privada. Os moradores dos loteamentos de acesso controlado tendem a um individualismo e egoísmo ao estabelecer que as necessidades individuais devem se sobrepor ao coletivo, surgindo uma massa de moradores que não encontram-se engajados em mudar a cidade e lutar para que benefícios e prejuízos sejam distribuídos de maneira igualitária.

O clima de insegurança e medo reinante hoje nas cidades participa do processo de desconexão das altas classes médias das funções de mediação, uma vez que incentiva a adoção de comportamentos auto defensivos e individualistas, que são, em último caso, de dessolidarização com os destinos da cidade (RIBEIRO, 2004, p.31).

O excesso de individualismo prejudica a formação de uma sociedade urbana (aqueles de dentro e de fora dos muros) coesa, com afinidades e relações sólidas de confiança e solidariedade. A segregação impulsiona o isolamento e a competição entre grupos diferentes. Do mesmo modo que o loteamento de acesso controlado materializa a segregação socioespacial no espaço da cidade marcando sua relação com o exterior, também materializa a coesão social e a eficácia coletiva, relação interna ao loteamento resultado dos efeitos de vizinhança.

Os moradores do LAC possuem características em comum desde o momento em que selecionam o lugar de morar, dependendo da renda familiar mensal e forma de pagamento da propriedade, escolhem a localização do loteamento, dimensões do terreno, as amenidades oferecidas pelo empreendimento, piscinas, quadras de esporte, salão de festas, praças, dentre outros. A renda familiar, a formação educacional, os hábitos culturais, os tipos de empregos integram os indivíduos que moram nos empreendimentos. Também há a busca por espaços protegidos e controlados, onde os considerados estranhos não podem ter livre acesso a menos que 
se identifique e seja autorizado por algum morador. A desconfiança é praticada diariamente como maneira de defender a segurança e a proteção contra o perigo que vem de fora.

Há aspectos que teoricamente intensificam a coesão social dentro do LAC, as características similares entre os indivíduos despertando sensação de confiança uns nos outros, aproximando-os e acreditando que estão em segurança diante da homogeneidade dos aspectos presentes na comunidade. O convívio nas áreas de uso comum, caminhadas nas vias, eventos organizados pelos moradores no salão de festas, atividades físicas na academia, encontro das crianças no parque, piscinas e quadras e a ausência de conflitos, pois os moradores estabelecem regras a serem seguidas em prol da ordem interna; todos estes são alguns dos elementos que possuem o potencial de ampliar os laços de confiança e de afeto entre os moradores.

Outros aspectos capazes de fortalecer a coesão social dentro dos LAC's são o compartilhamento de valores sociais, aquilo em que os indivíduos acreditam e defendem na sociedade; o controle informal em que os próprios moradores controlam atitudes desviantes sem a necessidade de intervenção externa e formal. A estabilidade residencial e propriedade da residência, evitando mudanças constantes de moradias, favorecem uma relação de vizinhança duradoura e confiável. Mas estes aspectos somente impulsionam a coesão desde que haja disposição dos membros da comunidade para conviver buscando o diálogo, a cooperação e a solidariedade. A coesão pode ser forte ou fraca a depender da frequência e intensidade dos laços formados, estes podem ser medidos com procedimentos empíricos em cada loteamento com suas características específicas.

Mas cada LAC possui sua maneira de funcionar, definição de usos e funcionamento das áreas comuns, regras de comportamento a serem obedecidas e punições para os desvios. É a não disposição e habilidade para conviver e cooperar dentro da comunidade que gera conflitos entre moradores enfraquecendo os laços, prejudicando a coesão. A própria maneira como o loteamento é idealizado e projetado é capaz de interferir no uso e experiência dos espaços; assim, percebe-se a integração do elemento espacial com o fenômeno social.

A coesão social é um dos efeitos da vizinhança e dependendo de sua intensidade pode gerar a eficácia coletiva. Quando um determinado grupo se une em busca de benefícios coletivos surge a eficácia, nos loteamentos de acesso controlado os moradores impõe suas demandas para o lugar onde moram e para isso há uma mobilização para alcançar aquilo que desejam para o coletivo. Ao reunir disposição, habilidade e competência o grupo estabelece os bens que se pretende conseguir e assim a eficácia coletiva acontece. Como dito, dentre os benefícios a serem alcançados encontram-se conserto de um equipamento da área de lazer, definição de horários para a realização de eventos no salão de festas, regras de uso da quadra de esportes, definição de punição para mal comportamento de moradores, elaboração do regimento interno, dentre outras possibilidades.

O importante para a eficácia coletiva é a vontade dos indivíduos de agir em prol do bem comum e assim definir o que é importante para a maioria dos envolvidos. É necessário haver cooperação, solidariedade e confiança para criar um ambiente coeso onde a eficácia possa se materializar em alcança de objetivos coletivos. Os moradores podem ter lugares específicos dentro do loteamento onde podem sentir-se mais coesos e onde poderão definir os bens a serem buscados para a melhoria do lugar. Da mesma forma que acontece com a coesão social, a eficácia coletiva pode ser mensurada através da maneira como a mobilização para alcançar determinado benefício acontece, a intensidade da rede de cooperação e se o benefício foi parcialmente ou plenamente alcançado.

Assim, é possível afirmar que há relações do loteamento de acesso controlado com o exterior, o fenômeno da segregação socioespacial materializa uma relação marcante que distancia o empreendimento de seu entorno. Há relações no interior do loteamento, entre moradores, resultado dos efeitos de vizinhança, sendo a coesão social e a eficácia coletiva os exemplos aqui citados. Cada loteamento apresentará resultados diferentes devido ao procedimento a ser aplicado para medir a intensidade de coesão social e eficácia coletiva o que permite alcançar resultados capazes de explicar a maneira como a coesão e a eficácia acontecem no interior do loteamento, em quais espaços e a partir de quais ações. 


\section{CONSIDERAÇÕES FINAIS}

O fato de um grupo de moradores decidir morar em loteamento de acesso controlado já demonstra objetivos comuns, seja a vontade de viver em um espaço protegido e tranquilo, a procura por equipamentos de lazer privativos, a distância do turbulento centro da cidade, ou a fuga da violência em crescimento. Os indivíduos que moram num mesmo loteamento tendem a identificar interesses e valores comuns e, assim, surge uma integração capaz de gerar a coesão social. A coesão se dá em diferentes níveis de intensidade podendo se materializar ou não em eficácia coletiva que é a capacidade de alcançar benefícios coletivos através de uma mobilização. Esses conceitos são analisados internamente ao empreendimento para desvendar os impactos dessa forma de morar nas cidades brasileiras, diante de um crescimento do interesse privado sobre o coletivo.

É frequente encontrar estudos que abordam os impactos negativos da implantação de loteamentos delimitados por muros, tais como: prejuízo na mobilidade por haver a interrupção de ruas e a restrição da circulação de pessoas no espaço; criação de áreas isoladas do resto da cidade que não dialogam com o entorno; existência do fenômeno da segregação socioespacial aglomerando em um mesmo espaço pessoas com características sociais e econômicas similares, demarcando áreas de homogeneização social; privatização do espaço público à medida que fecham ruas, praças e parques que deveriam ser de uso público; ampliação do perímetro urbano com a localização dos empreendimentos na periferia das cidades exigindo investimento alto na área de infraestrutura, etc. Conhecendo as consequências dos empreendimentos no espaço urbano, é importante desvendar os prejuízos na relação interpessoal que acontece intramuros dos loteamentos residenciais.

Este modo de morar surge na década de 1970 no Brasil e está em constante crescimento devido ao investimento de empresários do ramo da construção civil. O loteamento residencial horizontal fechado, de acordo com a legislação vigente, que nasce ilegalmente da lei 6766 de 1979, adquire a possibilidade de regularização com a lei 17.465 de 2017 e nela é considerado o loteamento de acesso controlado (LAC), espaço que oferece oportunidades de uma vida com moradia, área verde e equipamentos de lazer (playground, academia, piscina, etc.) privativos. O modo de morar em um LAC cria a oportunidade para os moradores obter um estilo de vida exclusivo, onde as pessoas possuem condições econômicas, valores, educação, cultura e hábitos similares, proporcionando relações de maior proximidade física e de interesses. Essas relações são possíveis, pois há um compartilhamento de espaço e de expectativas de vida entre os indivíduos que habitam o loteamento, que gera a coesão social em diferentes níveis. Quanto mais intensa for a coesão mais chances de transformar-se em eficácia coletiva.

A eficácia coletiva é o alcance de benefícios coletivos por um determinado grupo social; ela acontece quando indivíduos que estão integrados por laços de confiança e valores compartilhados (coesão social) se unem para alcançar um determinado objetivo que beneficiará a todos. Nos loteamentos residenciais, quando há eficácia coletiva, é importante descobrir de que maneira acontece, a partir de quais atitudes, quais espaços dentro do loteamento favorecem e quais benefícios são pretendidos e quais são alcançados. Desvendar aspectos particulares são possíveis através de uma observação e investigação mais próxima de uma comunidade específica, pois cada uma possui exemplos de eficácia de acordo com a realidade vivida.

Ainda que passíveis de regularização os LAC's são um problema para as cidades, intensificando as relações cada vez mais egoístas e individualistas, distantes da experiência da cidade e deixando de lado o interesse com os problemas vividos para fora dos muros. Os agentes imobiliários e construtores vendem os empreendimentos fechados como espaços para viver em comunidade, protegendo dos males do exterior, com investimento em amenidades intramuros e cercando todo o loteamento com muros e cercas num incentivo a um estilo de vida segregado e apartado das demais áreas da cidade.

Segundo as referências bibliográficas utilizadas, o loteamento de acesso controlado em sua proposta de criação de um espaço para vida em comunidade é um ambiente que propicia um alto nível de integração capaz de gerar a coesão social, com moradores vivendo relações de confiança e redes de solidariedade para manter o espaço organizado e controlado. Também é favorável à eficácia coletiva, com a mobilização para alcançar benefícios, tais como promoção de eventos, consertos de estruturas e elaboração de normas. Mas esse fechamento espacial impacta negativamente o convívio entre indivíduos moradores dos empreendimentos.

O excesso de homogeneização social e econômica provoca pouca tolerância às divergências e diferenças, com incentivo à competição ao invés de cooperação, gerando conflitos entre moradores por luta de poder nos espaços e nas tomadas de decisões, cumprimento de regras, pagamento de taxas, dentre outros, o que distancia os moradores de um mesmo loteamento. Tais conflitos dificultam a coesão social e a eficácia coletiva, pesquisando cada loteamento específico é possível desvendar de que maneira acontece a coesão e a eficácia, em quais espaços e quais ações e o que impede que altos níveis de coesão e eficácia aconteçam. 


\section{REFERÊNCIAS}

ARAPIRACA. Lei n. 2.770, 19 de outubro de 2011. Dispõe sobre parcelamento de solo urbano no município de Arapiraca, amplia 0 perímetro urbano e dá outras providências. Disponível em: http://web.arapiraca.al.gov.br/wpcontent/uploads/2017/03/LEI27702011PARCELAMENTODESOLOURBANONOMUNICIPIODEARAPICAAMPLIAOPERI METROURBANO.pdf. Acesso em 01 de maio de 2018.

BRASIL. Lei n. 4.591, 16 de dezembro de 1964. Dispõe sobre o condomínio em edificações e as incorporações imobiliárias. Publicado no DOU de 21.12.1964 e retificado em 1.2.1965. Disponível em: http://www.planalto.gov.br/ccivil 03/Leis/L4591.htm. Acesso em 10 de abril de 2018.

BRASIL. Lei n. 271, 28 de fevereiro de 1967. Dispõe sobre o loteamento urbano, responsabilidade do loteador, concessão de uso e espaço aéreo e da outras providências. Publicado no DOU de 28.2.1967. Disponível em: http://www.planalto.gov.br/ccivil 03/decreto-lei/Del0271.htm. Acesso em 10 de abril de 2018.

BRASIL. Lei n. 6.766, 19 de dezembro de 1979. Dispõe sobre o parcelamento do solo urbano e dá outras providências. Publicado no DOU de 20.12.79. Disponível em: http://www.planalto.gov.br/ccivil 03/Leis/l6766.htm. Acesso em $10 \mathrm{de}$ abril de 2018.

BRASIL. Lei n. 10.406, DE 10 DE JANEIRO DE 2002. Institui o Código Civil. Publicado no DOU de 11.01.2002. Disponível em: http://www.planalto.gov.br/ccivll_03/Leis/2002/L10406.htm. Acesso em 10 de abril de 2018.

BRASIL. Lei n. 13.465, 11 de julho de 2017. Dispõe sobre a regularização fundiária rural e urbana, sobre a liquidação de créditos concedidos aos assentados da reforma agrária e sobre a regularização fundiária no âmbito da Amazônia Legal; institui mecanismos para aprimorar a eficiência dos procedimentos de alienação de imóveis da União; altera as Leis nos 8.629 , de 25 de fevereiro de 1993, 13.001, de 20 de junho de 2014, 11.952, de 25 de junho de 2009, 13.340, de 28 de setembro de 2016, 8.666, de 21 de junho de 1993, 6.015, de 31 de dezembro de 1973, 12.512, de 14 de outubro de 2011,10.406, de 10 de janeiro de 2002 (Código Civil), 13.105, de 16 de março de 2015 (Código de Processo Civil), 11.977, de 7 de julho de 2009, 9.514, de 20 de novembro de 1997, 11.124, de 16 de junho de $2005,6.766$, de 19 de dezembro de 1979, 10.257, de 10 de julho de 2001, 12.651, de 25 de maio de 2012, 13.240, de 30 de dezembro de 2015, 9.636, de 15 de maio de 1998, 8.036, de 11 de maio de 1990, 13.139, de 26 de junho de 2015, 11.483, de 31 de maio de 2007 , e a 12.712, de 30 de agosto de 2012, a Medida Provisória no 2.220, de 4 de setembro de 2001, e os Decretos-Leis nos 2.398, de 21 de dezembro de 1987, 1.876, de 15 de julho de 1981, 9.760, de 5 de setembro de 1946, e 3.365, de 21 de junho de 1941; revoga dispositivos da Lei Complementar no76, de 6 de julho de 1993, e da Lei no 13.347, de 10 de outubro de 2016; e dá outras providências. Publicado no DOU de 8.09.2017. Disponível em: http://www.planalto.gov.br/ccivil 03/ ato2015-2018/2017/lei/13465.htm. Acesso em 10 de abril de 2018.

CALDEIRA, Teresa. Cidade de muros: crime, segregação e cidadania em São Paulo. São Paulo: Ed. 34/EDUSP, 2000.

CRUZ, Wilson Jose Antônio. Os entraves para o surgimento da eficácia coletiva: um estudo de casos em um aglomerado de Belo Horizonte. 190p. Tese (Doutorado em Sociologia) Universidade Federal de Minas Gerais, Belo Horizonte, 2010.

DAMASCENO, A. et al. Análise Espacial do Desenho Urbano Contemporâneo: O Processo de Evolução da Ocupação Urbana a partir da Expansão dos Empreendimentos Privados em Arapiraca/Al, Brasil. In: 7ํ Congresso Luso Brasileiro para o Planejamento Urbano, Regional, Integrado e Sustentável, 2016, Maceió. Anais... Maceió, p.1-12, 2016.

FREITAS, Eleusina. L. H. de. Loteamentos Fechados. 206p. Tese (doutorado em Arquitetura e Urbanismo, área de concentração Habitat) Universidade de São Paulo, São Paulo, 2008.

IBGE. Instituto Brasileiro de Geografia e Estatística. População de Arapiraca censo de 2010. Disponível em <https://cidades.ibge.gov.br/brasil/al/arapiraca/panorama> Acesso em janeiro de 2018.

MOTTA, Eduardo Marchetti. Fragmentação socioespacial: reflexões a partir de condomínios fechados e shopping centers em Belo Horizonte. In: XVII ENANPUR, 2017, São Paulo. Anais... São Paulo, p.1-15, 2017.

PRATES, Antônio Augusto Pereira. Redes sociais em comunidades de baixa renda: os efeitos diferenciais dos laços fracos e dos laços fortes. Revista de Administração Pública. Rio de Janeiro, v. 43, 2009, n. 5, p. 1117-1146.

PREFEITURA DE ARAPIRACA. Ofício no1436 de 26 de fevereiro de 2018. Informações sobre empreendimentos residenciais fechados. Arapiraca, 2018.

RIBEIRO, Luiz Cesar de Q. (org.) Metrópoles: entre a coesão e a fragmentação, a cooperação e o conflito. São Paulo: Fundação Perseu Abramo/Fase/Observatório das Metrópoles, 2004.

SAMPSON, Robert J. Great American city: Chicago and the enduring neighborhood effect. Chicago: The University of Chicago Press, 2011.

SAMPSON, R. J.; STEPHEN, S. R.; EARLS, F. Neighborhoods and violent crime: a multilevel study of Collective Efficacy. Science, Washington, v. 277, 1997, p. 918-924.

SCIOTA, Alessandra A. Critérios de Avaliação de Morfologia Urbana em Modelos de Segregação Residencial. Tese (doutorado em Urbanismo no Centro de Ciências Exatas, Ambientais e de Tecnologia) Pontifícia Universidade Católica de Campinas, Campinas, 2016. 
SORJ, Bernardo; MARTUCCELLI, Danilo. O Desafio Latino-Americano: coesão social e democracia. Rio de Janeiro: Civilização Brasileira, 2008.

SOUZA, Marcelo Lopes de. O desafio metropolitano: um estudo sobre a problemática sócio-espacial nas metrópoles brasileira. Rio de Janeiro: Bertrand Brasil, 2005.

ZALUAR, Alba; RIBEIRO, Ana Paula Alves. Teoria da eficácia coletiva e violência: o paradoxo do subúrbio carioca. Novos Estudos-CEBRAP, 2009, n. 84, p. 175-196.

\section{NOTAS}

1 Disponível em https://geo.arapiraca.al.gov.br/geo/geoweb/ acesso em 10 de abril de 2018.

NOTA DO EDITOR (*) O conteúdo do artigo e as imagens nele publicadas são de responsabilidade do(s) autor(es). 